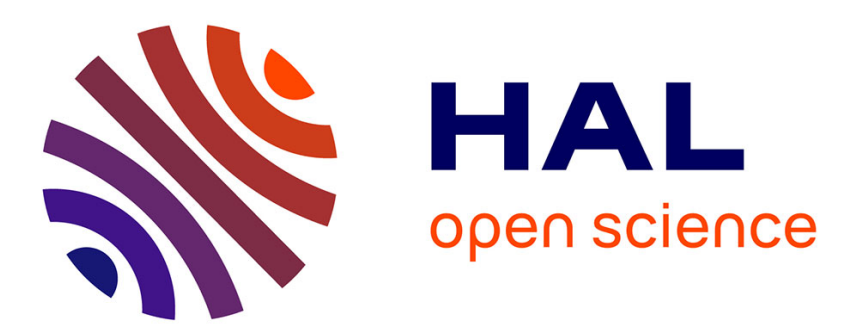

\title{
Decentralized licensing of complementary patents: Comparing the royalty, fixed-fee and two-part tariff regimes
}

\author{
Yann Ménière, Sarah Parlane
}

\section{- To cite this version:}

Yann Ménière, Sarah Parlane. Decentralized licensing of complementary patents: Comparing the royalty, fixed-fee and two-part tariff regimes. Information Economics and Policy, 2010, 22 (2), pp.178191. 10.1016/j.infoecopol.2009.10.003 . hal-00460754

HAL Id: hal-00460754

https://hal-mines-paristech.archives-ouvertes.fr/hal-00460754

Submitted on 2 Mar 2010

HAL is a multi-disciplinary open access archive for the deposit and dissemination of scientific research documents, whether they are published or not. The documents may come from teaching and research institutions in France or abroad, or from public or private research centers.
L'archive ouverte pluridisciplinaire HAL, est destinée au dépôt et à la diffusion de documents scientifiques de niveau recherche, publiés ou non, émanant des établissements d'enseignement et de recherche français ou étrangers, des laboratoires publics ou privés. 


\title{
Decentralized licensing of complementary patents: Comparing the royalty, fixed-fee and two-part tariff regimes.
}

\section{Yann MENIERE ${ }^{1}$ and Sarah PARLANE ${ }^{2}$.}

September 28, 2009

\begin{abstract}
This paper explores the decentralized licensing of complementary patents reading on a technology standard. We develop a model in which manufacturers must buy licenses from different patent owners in order to enter the market for differentiated standard-compliant products. We consider three different types of licensing, namely, the fixed-fee, per-unit royalty and two-part tariff regimes, and compare their performances in terms of licensing revenue, price, product variety and welfare. We show that each regime entails different types of coordination failures. We establish that each of them may maximize the licensing revenue depending on the number of licensors, number of potential entrants and product differentiation.
\end{abstract}

\footnotetext{
${ }^{1}$ Dr. Yann Ménière, Cerna, MINES ParisTech, 60 bd St Michel, 75006 Paris, France. (email: yann.meniere@ensmp.fr)

${ }^{2}$ Dr. Sarah Parlane, School of Economics, University College Dublin, Belfield, Dublin 4, Ireland. (email: Sarah.parlane@ucd.ie)
} 


\section{Introduction}

Cooperative technology standards frequently embody complementary patents belonging to various owners. Over the last two decades, the number of such patents has increased steeply (Bekkers et al., 2002; Simcoe, 2005), thereby raising a royalty stacking problem, also known as a "double marginalization" or the "Cournot-Shapiro" issue. Each patent owner enjoys a monopoly position and can therefore charge its licensees high royalties. However, patent owners who do this fail to take into account that they also reduce the demand for licenses on other complementary patents. The resulting royalty stacking induces not only a decrease in demand for standard-compliant technologies, but also lower profits for the patent owners themselves. It would be more profitable for the patent owners to form a "patent pool" by which they can grant a single package license for the bundle of their patents, and share the resulting licensing revenue (Shapiro, 2001).

In this paper, we explore whether the coordination failure featuring the "Cournot-Shapiro" issue may apply to licenses based on schemes other than royalty. In practise, patent owners may use alternative schemes-such as fixedfee or, more frequently, a combination of fixed-fee and royalty (two-part tariff)to license patents reading on standards. ${ }^{3}$ We analyze each of these schemes in

\footnotetext{
${ }^{3}$ Contracts used to license patents relating to standards are seldom publicized. Yet statements by Qualcomm and Interdigital, two major patent owners in wireless communication standards, highlight the variety of licensing contracts. "We derive the majority of our revenue from patent licensing. ... These agreements can include, without limitation ... up-front and non-refundable license fees and/or ... licensing royalties on covered products sold by licensees" (Interdigital Annual Report, 2009). "In the wireless industry, both handset makers and chipmakers commonly pay licensing fees in the form of an up-front license fee and a running royalty that is a percentage of the selling price of the product sold, or some combination
} 
turn, to highlight possible coordination failures when numerous complementary patents are licensed in a decentralized fashion. We compare them as a second step in identifying which one is more efficient from joint-profit and social welfare perspectives. Using the best licensing scheme is an interesting alternative to patent pools since the latter frequently fail to form in practice. ${ }^{4}$ Our results suggest especially that the notion of "reasonable" licensing ${ }^{5}$ should be associated with particular schemes depending on the number of patents owners and the structure of the market for standard-compliant goods.

To carry out the analysis, we develop a model in which $\chi \geq 1$ owners of complementary patents reading on a new standard sell their licenses to manufacturers of standard-compliant products. Manufacturers must buy a license on each patent before starting production. Consistent with the "non-discriminatory" licensing requirements usually imposed on patents reading on standards, we assume that patent owners must grant a license to each manufacturer who is willing to pay on the same terms as the other licensees.

While the "Cournot-Shapiro" issue has so far been characterized in the case of homogenous products (Shapiro, 2001), we allow for horizontal differentiation in the product market. This assumption better captures the type of products complying with standards in information technologies. ${ }^{6}$. Moreover, it has im-

of the two." (Brief of Qualcomm Inc. As Amicus Curiae in Support of Respondent, December 10, 2007)

${ }^{4}$ Patent owners have strong incentives to stay out of a pool in order to ride freely on the low price of the package license by charging a higher price for their own patents (Aoki \& Nagaoka, 2004).

${ }^{5}$ The intellectual property policies of most standard-setting organizations require that patent owners license their patents under fair, reasonable and non-discriminatory terms (Lemley, 2002).

${ }^{6}$ Horizontal differentiation is key in markets for video and music contents, covered by 
portant implications with respect to the licensing regimes.

Indeed, we show that the royalty and fixed-fee regimes are more or less appealing for licensors depending on the degree of product differentiation. A fixed-fee regime imposes an entry cost to manufacturers and is therefore a way for patent owners to control the number of licensees and to extract all possible profits. By contrast, patent owners cannot use per-unit royalties to control entry, or to extract all profits. Yet royalties increase marginal manufacturing costs, and therefore allow patent owners to monitor market prices for a given number of manufacturers.

If there is only one patent owner, charging a high fixed fee is a way to allow one licensee only and thus to reap the monopoly profit when products are homogenous. As products get more differentiated, however, it becomes more profitable to use royalties. A larger number of manufacturers can then enter the market, price competition being mitigated by per-unit royalties. Not surprisingly, we find that a single licensor will always prefer the two-part tariff to the fixed-fee or royalty regime alone, since it combines the best of both worlds.

Our main finding is that introducing additional patent owners (e.g. $\chi>$ 1) in this setting can generate some coordination failures with each type of licensing regime. As a general rule, total licensing revenue is non-increasing in $\chi$, irrespective of the licensing scheme. Although fixed-fee payments do not distort competitive prices, their stacking has a negative entry deterrence effect. In turn, the two-part tariff regime combines coordination failures pertaining to standards such as MPEG, DVD, or BlueRay. The same is true for mobile phones (GSM, EDGE, or $3 \mathrm{G}$ standards), although then vertical differentiation may also play a role. 
both royalty and fixed-fee stacking.

Comparing the three regimes with $\chi>1$, we find that each type of license may maximize total licensing revenue depending on the degree of product differentiation. Fixed-fees only and two-part tariff are more profitable respectively for weakly and strongly differentiated products. We show that pure royalties dominate both fixed-fee and two-part tariff regimes for intermediate levels of differentiation. These findings are consistent with available evidence: patent owners rely on the pure royalty or two-part tariff regimes to reach a large number of differentiated licensees. ${ }^{7}$

These results are new in the literature on the licensing of complementary patents. The coordination failure resulting from the decentralized licensing of complementary patents has been pinpointed by Shapiro (2001) in the case of royalty-based licenses only, and discussed further in papers on patent pools (Lerner \& Tirole, 2004; Lerner et al., 2005; Aoki \& Nagaoka, 2004). Yet to our knowledge, potential coordination failures with other licensing schemes have not been explored, although they may have useful implications in terms of selection of license. Our approach also relates to the literature on optimal licensing.

Many papers (see Sen (2005) for a good review) compare auctions, royalty and fixed-fee licenses in the trail of the seminal contribution of Kamien and Tauman $(1986,1992)$, who found the fixed fee to be superior. There papers usually rely on the distinction between drastic and non-drastic cost-reducing

\footnotetext{
${ }^{7}$ Since bilateral licensing contracts are usually kept secret, we rely for evidence on the licenses publicized by some patent pools. These pools involve a subgroup of the patent owners. All of them have opted for either pure royalty (DVD6C, and MPEG-LA patent pools) or twopart tariff (Blue-Ray encryption standard).
} 
innovations, which may be licensed either by a single external patentee (Kamien and Tauman, 1986, 1992, Muto, 1993, Poddar \& Sinha, 2004, Erutku \& Richelle, 2007) or by competitors (Wang, 1998, Poddar \& Sinha, 2004, Erkal, 2005). We in turn consider the licensing by several external patentees of a standard embodying complementary innovations. Since the standard opens a new market for licensees, it does not match the definition of non-drastic and drastic costreducing innovations, although in effect it is closer to the latter. Muto (1993) and Poddar and Sinha (2004) show that an external patentee may prefer a royalty regime when products are differentiated, in Bertrand and linear city competition settings. We extend this result to differentiation in a Cournot model, with one or more complementary patents ${ }^{8}$. Erutku and Richelle (2007) introduce the two-part tariff in a model derived from Kamien and Tauman (1986) and show that it always dominates the other schemes. Our analysis confirms their result, but highlights its limitation when several licensors are involved.

This article is organized in six sections. Section 2 introduces the model. In section 3 we solve the licensing equilibria for each type of licensing scheme, and highlight different coordination failures when there is more than one patent owner. We then compare the three licensing schemes in the next two sections, with regard to licensing revenue (section 4) and social value of the standard (section 5). Section 6 concludes.

\footnotetext{
${ }^{8}$ Caballero-Sanz et al. (2002) also consider a model of optimal licensing with product differentiation and a single licensor.
} 


\section{The model}

In this section, we introduce our general model. We consider a market for products compliant with a technology standard. The standard incorporates $\chi$ patented technologies belonging to $\chi$ independent owners. The $\chi$ patents are essential, so that each manufacturer of a standard-compliant product must license all patents to enter the product market. Patent owners are not involved in product manufacturing, and simply seek to maximize their profits through licensing.

To enter the market, manufacturers of standard-compliant products must buy a license on each patent. We assume that $n(n \in N$ and $n \geq 1)$ symmetric firms are capable of using the standard to produce differentiated outputs, $k$ of which will eventually enter the market. We consider that there is imperfect competition on the product market and assume that manufacturers compete à la Cournot. The total cost function for each producer is linear and such that $T C(q)=c q$.

The demand for these products comes from a representative consumer who has rational preferences characterized by the following utility function:

$$
U\left(q_{1}, \ldots, q_{k}\right)=a \sum_{i=1, \ldots, k} q_{i}-\frac{1}{2} \sum_{i=1, \ldots k}\left[\left(q_{i}\right)^{2}+\alpha q_{i}\left(\sum_{\substack{j=1, \ldots k \\ j \neq i}} q_{j}\right)\right]
$$

where $a>c$ is a constant and $\alpha \in[0,1]$ measures product substitutability. Maximizing the utility subject to budget constraint allows us to determine the 
demand for product $i$ when $k$ products are available. It is given by:

$$
p_{i}\left(q_{i}, Q_{-i}\right)=a-q_{i}-\alpha Q_{-i},
$$

where $i=1, \ldots, k$ and $Q_{-i}=\sum_{j \neq i} q_{j}$.

We consider three possible licensing regimes: fixed-fee only, royalty only or two-part tariff. The timing is the following. First the patent holder announces the patent policy stating the fixed fee $l \geq 0$ and royalty $r \geq 0$. By definition the fixed-fee regime has $r=0$, the royalty regime has $l=0$ while two-part tariff has $r>0$ and $l>0$. Second, the firms decide whether to buy the licence. We consider that they derive 0 profit without a license. When $l>0$ we consider that entry is determined by a 0 profit condition since profits are decreasing in the number of firms. We let $1 \leq k \leq n$ denote the number of firms who purchase the licenses. Third, if $k>1$, the firms compete à la Cournot, and if $k=1$ the firm sets its monopoly price and quantity.

Although the number $k$ of licensees is by definition an integer, we study it as a real number throughout the rest of this paper. However, we consider that $k$ must be at least equal to 1 for the patent owners to make any profits and that $k \leq n$. By considering any $k \in[1, n]$ we skip the comparison of the closest upper and lower integer bounds of $k$, which simplifies the analysis. 


\subsection{Output, price and profits}

We search for a sub-game perfect Nash equilibrium and solve the game backwards. Let $L=\sum_{s=1, \ldots, \chi} l_{s}$ and $R=\sum_{s=1, \ldots, \chi} r_{s}$. The fixed-fee $L$ is a cost paid up front. It affects the Cournot outcome by determining the number of licensees $k$ who compete. Let $\pi(k, R)$ denote the Cournot profit when $k$ firms

compete and the royalties amount to $R \geq 0$. Since $\frac{\partial \pi}{\partial k}<0$ for any $L>0$ there is a unique $k^{*}$ such that

$$
\pi\left(k^{*}, R\right)-L=0
$$

In a free entry equilibrium $k$ firms purchase the license where $k=\min \left\{k^{*}, n\right\}$.

Each firm then solves

$$
\begin{gathered}
\max _{q_{i}}\left[a-q_{i}-\alpha Q_{-i}\right] q_{i}-(c+R) q_{i}, \\
\text { where } Q_{-i}=\sum_{\substack{j=1, \ldots, k \\
j \neq i}} q_{j}
\end{gathered}
$$

Observe that the parameter $\alpha$, denoting product differentiation, confers a local market power to each firm. The unique symmetric equilibrium is such that

$$
q(k, R)=\left\{\begin{array}{l}
\left(\frac{a-c-R}{2+\alpha(k-1)}\right) \text { if } R<a-c, \\
0 \text { otherwise. }
\end{array}\right.
$$

The resulting symmetric price, provided there is production, is such that

$$
p(k, R)-(c+R)=q(k, R) .
$$


Observe that the output per firm and the margin per unit of output are increasing in the degree of product differentiation $1 / \alpha$. Therefore the equilibrium profit is also increasing with product differentiation:

$$
\pi(k, R)=\left\{\begin{array}{l}
\left(\frac{a-c-R}{2+\alpha(k-1)}\right)^{2} \text { if } R<a-c \\
0 \text { otherwise. }
\end{array}\right.
$$

\section{Licensing strategies at equilibrium}

The separate licensing of complementary innovations has been studied thus far only in the case of royalty-based licenses. We solve this case in this section and extend the analysis to licenses based on a fixed-fee scheme and on twopart tariff. We characterize the profit maximizing licensing contract for each of the three different regimes. To identify the possible coordination failures, we analyze in each case how the total licensing revenue varies with the number of patent owners.

\subsection{Royalty regime}

Let $\left(k^{R}, r_{1}^{R}, \ldots, r_{\chi}^{R}\right)$ denote the profit maximizing number of licensees and royalty under this regime. The profit of licensor $s(s=1, \ldots, \chi)$ is

$$
\Pi^{R}\left(r_{s}, r_{-s}\right)=k \cdot r_{s} \cdot q\left(k, r_{s}, r_{-s}\right),
$$

where $r_{s}$ denotes the royalty charged by licensor $s, r_{-s}=\sum_{j \neq s} r_{j}$, and $q(k, R)$ is given by (3). From (3) and (4) we deduce that $n$ manufacturers will enter if 
$R \leq a-c$, and none otherwise. Consequently licensor $s$ maximizes the following expression:

$$
\Pi^{R}\left(r_{s}, r_{-s}\right)=\left\{\begin{array}{l}
r_{s} \cdot n \cdot \frac{a-c-r_{s}-r_{-s}}{2+\alpha(n-1)} \text { if } r_{s} \leq a-c-r_{-s} \\
0 \text { otherwise. }
\end{array}\right.
$$

It can easily be verified that individual royalties charged by patent owners are strategic substitutes. Proposition 1 describes the symmetric equilibrium.

Proposition 1: In a royalty regime, there is a unique symmetric equilibrium in which $n$ manufacturers enter. The individual royalties and licensing profits are then given by:

$$
\begin{gathered}
r^{R}=\frac{a-c}{1+\chi} \\
\Pi^{R}=\frac{n}{2+\alpha(n-1)}\left(\frac{a-c}{1+\chi}\right)^{2} .
\end{gathered}
$$

Proof: Obvious and thus omitted.

The number of licensors decreases along with individual royalties and profits. Lemma 1 below displays the effect of $\chi$ on cumulative royalties $\left(R^{R}=\chi r^{R}\right)$ and licensing profits $\left(\chi \Pi^{R}\right)$.

Lemma 1: In a royalty regime, the cumulative royalty paid by manufacturers (i.e. $\chi^{R}$ ) is increasing in $\chi$, while the cumulative profit of licensors is decreasing in $\chi$.

Proof: Obvious and thus omitted.

This result captures the double marginalization problem that arises when 
complementary patents are licensed separately (Shapiro, 2001). Each licensor charges a mark-up without taking into account that a mark-up reduces the demand for other licensors. At the equilibrium, cumulative royalties are too high and reducing them would increase the total licensing profits. In this context, a merger between the patent owners or, which may be more realistic, the creation of a patent pool, increases the patent owners' profits.

\subsection{Fixed-fee regime}

Let $\left(k^{F}, l_{1}^{F}, \ldots, l_{\chi}^{F}\right)$ denote the profit-maximizing number of licensees and fixed fees under this regime. Under free entry fixed fees permit full extraction of the firms' profit. Note that the cumulative fee $L=\sum_{s=1, \ldots, \chi} l_{s}$ determines the number $k^{F}$ of competing manufacturers at equilibrium. All $n$ firms will enter if $L \leq \pi(n, 0)$. For any $L>\pi(n, 0)$ there is a unique $k^{F}<n$ such that (2) holds and we have $\pi\left(k^{F}, 0\right)=L$.

Proposition 2: There exists a symmetric equilibrium characterized as follows:

$$
k^{F}=\left\{\begin{array}{l}
n \text { for } \alpha \leq \frac{2}{(2 \chi-1) n+1} \\
\left.\frac{2-\alpha}{\alpha(2 \chi-1)} \text { for } \alpha \in\right] \frac{2}{(2 \chi-1) n+1}, \frac{1}{\chi}[ \\
1 \text { for } \alpha \geq \frac{1}{\chi}
\end{array}\right.
$$

and

$$
l^{F}=\frac{1}{\chi} \pi\left(k^{F}, 0\right)
$$

Proof: See Appendix. 
Before discussing these results, it is useful to consider the case in which there is only one patent owner described in the corollary below.

Corollary 1: For the case $\chi=1$ we have

$$
k^{F}=\left\{\begin{array}{l}
n \text { for } \alpha \leq \frac{2}{n+1} \\
\left.\left.\frac{2-\alpha}{\alpha} \text { for } \alpha \in\right] \frac{2}{n+1}, 1\right] .
\end{array}\right.
$$

Proof: Set $\chi=1$ in the proof of Proposition 2.

When products are homogenous $(\alpha=1)$ the monopoly is clearly the profitmaximizing market structure and the licensor allows only one entrant. As products become more differentiated $\left(\frac{2}{n+1}<\alpha<1\right)$, the licensor's incentive to sell more than one licence is due to the additional licensing profits generated by product variety and $k^{F}$ is thus increasing in the degree of differentiation $(1 / \alpha)$. The equilibrium number of licensees results from a trade-off between product variety and price competition. Any increase of the fee entails an increase in the profit per licensee, but also a decrease in the number of entrants, and thus less variety. As product differentiation increases, the second effect becomes more important and more licenses are issued. Beyond a certain threshold of product differentiation $(\alpha \leq 2 /(n+1))$, it is profitable to set $k=n$.

We can now turn again to Proposition 2, and examine specifically the case $\chi>1$. We can still observe the equilibria identified with a unique licensor, but the number of patent owners now modifies both the intervals over which the equilibria take place and the number of entrants in the second equilibrium. When $\alpha$ is such that we have $1<k^{F}<n$ entrants in equilibrium, the number 
of entrants is decreasing in the number of licensors. Indeed, the cumulative fees increase with $\chi$, which denotes a coordination failure, and induces fewer entrants for a given $\alpha$. While $k^{F}=1$ was only optimal for $\alpha=1$ when we had only one license holder, it now occurs for a wider range of product differentiation. In other words, entry is now restricted to one licensee only when products are weakly differentiated, and products need to be more differentiated for all $n$ candidates to be allowed into the market.

Lemma 2: Let $\chi \Pi^{F}=\sum_{s=1, \ldots, \chi} l_{s}^{*}$ denote the cumulative licensing profit in a fixed-fee regime:

1-For $\alpha \leq \frac{2}{(2 \chi-1) n+1}$, and $\alpha \in\left[\frac{1}{\chi}, 1\right]$, the cumulative licensing profit $\chi \Pi^{F}$ does not depend on $\chi$.

2-For $\alpha \in\left[\frac{2}{(2 \chi-1) n+1}, \frac{1}{\chi}\right]$, the cumulative licensing profit $\chi \Pi^{F}$ is decreasing in $\chi$.

Proof: Obvious and thus omitted.

Lemma 2 states that the total licensing revenue is non-increasing with respect to the number of patent owners. More precisely, adding patent owners reduces the total licensing revenue when it effectively deters entry. When differentiation is very strong so that $n$ licenses are granted, increasing $\chi$ will not affect licensing revenues until the threshold $\alpha=\frac{2}{(2 \chi-1) n+1}$ is reached. Finally, when there is only one licensee left, increasing the sum of fixed fees would kill the market so that patent owners would have to adjust their fees and their total revenue would remain constant. 


\subsection{Two-part tariff}

Let $\left(k^{T}, l_{1}^{T}, \ldots, l_{\chi}^{T}, r^{T}\right)$ denote the profit-maximizing number of licensees, fixed fees and royalty under this regime. A two-part tariff regime allows the licensors to control the number of manufacturers through the fixed fee, and the product prices through the royalties.

Proposition 3: The following fixed fee and royalty form the unique symmetric Nash equilibrium.

1- For all $\alpha \leq \frac{1}{\chi}$ we have

$$
r^{T}=\frac{\alpha(n-1)(a-c)}{2+\alpha(n-1)(\chi+1)} \text { and } l^{T}=\frac{1}{\chi}\left(\frac{a-c}{2+\alpha(n-1)(\chi+1)}\right)^{2} .
$$

and $k^{T}=n$.

2-For $\left.\alpha \in] \frac{1}{\chi}, 1\right]$ the optimal royalty level is zero and the licensors use a fixed-fee regime with $l^{T}=\frac{(a-c)^{2}}{4 \chi}$ and $k^{T}=1$.

Proof: See Appendix.

As with the fixed-fee license, it is useful to consider first the case of a unique patent owner.

Corollary 2: Two-part tariff with a single licensor.

A single licensor systematically sells $n$ licenses and sets

$$
r^{T}=\frac{\alpha(n-1)(a-c)}{2+2 \alpha(n-1)} \text { and } l^{T}=\left(\frac{a-c}{2+2 \alpha(n-1)}\right)^{2} .
$$

Proof: Set $X=1$ in the results of Proposition 3. 
It is interesting to note that when products are homogenous $(\alpha=1)$, the royalty and fixed fee are such that the licensor extracts

$$
\Pi^{T}=\frac{(a-c)^{2}}{4}
$$

which is equal to the monopoly rents. The two-part tariff makes it possible to derive the maximum benefit of product variety while avoiding rent dissipation through competition between licensees. To do so, the licensor uses the royalty to monitor competitive prices, and the fixed-fee license to extract all market profits. It can easily be verified that the per-unit royalty then decreases in the degree of product differentiation (since differentiation increasingly mitigates price competition) while the fixed-fee license increases in parallel (because the market profit per licensee increases with differentiation).

We now analyze what happens when $\chi>1$. As Lemma 3 states, under twopart tariff a licensor's revenue is either monotonically increasing or decreasing in $k$.

Lemma 3: In an equilibrium with a positive royalty $\left(r^{*}>0\right)$ and a positive fixed fee $\left(l^{*}>0\right)$ the total licensing profit $\Pi^{T}$ increases with $k$ if $\chi \leq \frac{1}{\alpha}$ and decreases otherwise.

Proof: See Appendix.

The threshold $\chi=1 / \alpha$ identified in Lemma 3 corresponds exactly to the threshold where the licensing equilibrium shifts from full entry to $k^{*}=1$ in Proposition 3. When they are too numerous, patent owners fail to coordinate 
and thus extract less profits from product variety. They are then better off limiting entry to one licensee and sharing the resulting monopoly profit. Since this shift proceeds from individual trade-offs between the benefit of variety and the cost coordination failure, the threshold of $\chi$ above which it takes place is higher the more differentiated the products.

Lemma 4: The cumulative licensing profit with two-part tariff is given by:

$$
\chi \Pi^{T}=\frac{n(a-c)^{2}(1+\alpha \chi(n-1))}{[2+\alpha(n-1)(\chi+1)]^{2}},
$$

where $\alpha \leq \frac{1}{\chi}$. It is thus decreasing in $\chi$.

Proof: Obvious and thus omitted.

\section{Comparing the different regimes}

Having characterized the equilibria and coordination issues with each of the licensing regimes, we now compare total licensing revenues of patent owners within these regimes. For clarity, we first consider the case of a single patent owner, and then extend the analysis to multiple patent owners.

\subsection{Monopolistic license ownership.}

Assume that $\chi=1$, meaning either that there is a single patent owner or that all patent owners form a patent pool. Before considering the two-part tariff, we first compare the fixed-fee and royalty regimes. We establish in Proposition 4 that each regime can maximize the total licensing revenue depending on the 
level of product differentiation.

Proposition 4: The royalty regime leads to higher profits than the fixed-fee regime provided $n \geq 6$ and $\alpha \in[\underline{\alpha}, \bar{\alpha}]$, where

$$
\underline{\alpha}=\frac{n+1-\sqrt{n^{2}+1-6 n}}{2 n} \text { and } \bar{\alpha}=\frac{n+1+\sqrt{n^{2}+1-6 n}}{2 n}
$$

For any other combinations of $\alpha$ and $n$ the fixed-fee regime dominates the royalty regime.

Proof: See Appendix.

When the standard either supports nearly independent products $(\alpha<\underline{\alpha})$ or appeals to very few users ( $n$ low), a fixed-fee license granted to all is superior to a royalty-based license because it makes it possible to extract all of the (close to) monopoly profits from each licensee ${ }^{9}$. Aside from these two situations, the fixed-fee regime does not systematically maximize profits. For any given $k$ sold licenses, the licensing revenue decreases with price competition as the product become more homogeneous $(\alpha \rightarrow 1)$. Reducing the number of licensees through fixed-fees is a way to mitigate price competition, but it prevents the licensor from deriving a profit from product variety when differentiation is substantial. By contrast, the royalty regime triggers full entry, but enables the licensor to mitigate price competition through the impact of royalties on marginal production costs. When products are differentiated yet not independent $(\alpha \in[\underline{\alpha}, \bar{\alpha}])$,

\footnotetext{
${ }^{9}$ Note that as $\alpha \rightarrow 1$, we find that the fixed fee is superior because the licensor limits entry to only one firm. This corresponds to the findings of Kamien and Tauman (1986).
} 
a royalty is the best way to extract a licensing revenue from product variety provided potential entrants are numerous $(n \geq 6)$. Finally, if we consider the two-part tariff, the following result is evident. Recall that with $\chi=1$, the twopart tariff regime is well defined (i.e.l $>0$ and $r>0$ ) and has $k=n$ for all $\alpha \in[0,1]$.

Lemma 5: The two-part tariff regime dominates both the fixed-fee and the royalty regimes

Proof: obvious and thus omitted.

The two-part tariff regime allows the licensor to combine the advantages of both the fixed-fee and royalty regimes. The licensor uses royalties to neutralize price competition between licensees, and sets the fixed-fee so as to extract the full industry profits.

\subsection{Decentralized licensing.}

We have seen that multiple licensors generate coordination failures resulting in profit losses for each of the three regimes. The cumulative licensing profits are compared in Proposition 5 below.

\section{Proposition 5:}

1-For any $\alpha \in\left[0, \frac{2}{(2 \chi-1) n+1}\right]$, we have $\chi \Pi^{T}>\chi \Pi^{F}>\chi \Pi^{R}$.

2-For any $\left.\alpha \in] \frac{2}{(2 \chi-1) n+1}, \frac{1}{\chi}\right]$ the two-part tariff dominates both the fixedfee and royalty regimes. Moreover, there exists a unique $n_{1}(\alpha, \chi)$ such that $\chi \Pi^{R}>\chi \Pi^{F}$ if and only if $n>n_{1}(\alpha, \chi)$. 
3-Consider any $\left.\alpha \in] \frac{1}{\chi}, 1\right]$. Over that interval only the fixed-fee and the royalty regimes are relevant. We show that

(i) for $\alpha \in] \frac{1}{\chi}, \frac{4 \chi}{(1+\chi)^{2}}\left[\right.$ there exists a unique $n_{2}(\alpha, \chi)$ such that $\chi \Pi^{R}>\chi \Pi^{F}$ if and only if $n>n_{2}(\alpha, \chi)$.

(ii) for $\alpha \in\left[\frac{4 \chi}{(1+\chi)^{2}}, 1\right]$ we have $\chi \Pi^{R}<\chi \Pi^{F}$.

Proof: See Appendix.

Table 1 below summarizes which is the overall profit-maximizing regime.

\begin{tabular}{|l|l|}
\hline$\alpha$ & Profit maximizing regime $(\chi \geq 2)$ \\
\hline$\left[0, \frac{1}{\chi}\right]$ & Two-part tariff $\left(k^{T}=n\right)$ \\
\hline$\left[\frac{1}{\chi}, \frac{4 \chi}{(1+\chi)^{2}}\right]$ & $\left\{\begin{array}{c}\text { Fixed fee }\left(k^{F}=1\right) \text { if } n<n_{2} \\
\text { Royalty }\left(k^{R}=n\right) \text { if } n>n_{2}\end{array}\right.$ \\
\hline$\left[\frac{4 \chi}{(1+\chi)^{2}}, 1\right]$ & Fixed fee $\left(k^{F}=1\right)$. \\
\hline
\end{tabular}

Table 1.

For a given number of patent owners $\chi>1$, the profit maximizing licensing scheme varies depending on the degree of product differentiation $(\alpha)$ and on the number of potential entrants $(n)$. The two-part tariff regime dominates both the fixed-fee and royalty regimes, because this regime helps to control coordination issues and limits the losses they generate.

A pure fixed-fee regime dominates the royalty regime for low levels of differentiation $\left(\alpha>4 \chi(1+\chi)^{-2}\right)$ by inducing a monopolistic market structure downstream and avoiding the price distortions induced by positive royalties. Similarly, this regime makes it possible to extract close to monopoly rents when products are sufficiently differentiated $\left(\alpha<\frac{2}{(2 \chi-1) n+1}\right)$. In this particular case, 
where the latter regime raises revenue by inducing more product varieties, the fixed-fee regime performs better than the royalty regime but not as well as a two-part tariff regime.

For intermediate values of product differentiation, product variety can become an important source of profits. Therefore, when $n$ is large enough $\left(n>n_{2}\right.$ or $n>n_{1}$ depending on whether $\alpha$ is greater or less than $\frac{1}{\chi}$ ), the royalty regime performs better than the fixed-fee regime.

\section{Total surplus}

In this section we focus on social welfare by introducing consumer welfare into the analysis. Note here that patent owners are legally entitled to maximize their profits, since this maximizes their incentives to innovate. Therefore, they should be allowed to select the licensing scheme accordingly. It is nevertheless of interest to study how their choice may affect static social welfare. We first highlight the main trade-off underlying the social surplus problem, and then use simulations to compare the licensing regime.

\subsection{Comparing product prices and variety}

There is no clear hierarchy between the three licensing regimes as regards consumers' welfare. As stated in Proposition 6, product prices on the one hand, and product variety on the other, are ranked strictly inversely.

Proposition 6: Prices and variety on the product market are ranked such 
that

$$
\begin{aligned}
& k^{F} \leq k^{T} \leq k^{R} \\
& p^{F} \leq p^{T}<p^{R}
\end{aligned}
$$

Proof: See Appendix.

Observe first that product variety is always lower with fixed-fee regimes than with two-part tariffs, and with two-part tariffs than with royalties. This is not surprising since profit maximization with fixed fees is entirely based on entry limitation, which is only partly the case with two-part tariff and not at all with pure royalties. The ranking of prices is identical. This would be straightforward under an equal number of licensees, for royalties increase the cost and thus the price. Yet Proposition 6 extends this intuition to the seemingly more ambiguous cases where the number of competitors is restricted below $\mathrm{n}$ due to a positive fixed fee.

\subsection{Welfare comparison}

Given that the three regimes have contrasting advantages in terms of products, prices and variety, ranking them requires a full analysis of social surplus. Such analysis is complex and makes it more difficult to obtain clear results. We therefore limit our analysis to the numeric simulations with $\chi=1$ and $\chi=2$, and show that welfare comparison is then consistent with our results on profit comparison. 
To introduce the consumers' surplus in the welfare analysis, we know from Vives (1999) that the total surplus in an economy with differentiated items with linear costs and linear demand can be written as

$$
T S^{r}=U\left(q_{1}^{r}, \ldots, q_{k^{r}}^{r}\right)-\sum_{i=1, \ldots k^{r}} c q_{i}^{r}
$$

where $r$ stands for the regime under consideration $(r=F, R, T)$ and $U($.$) is$ given by (1). Given that output is symmetric, we can rewrite the total surplus as:

$$
U(q, k)=(a-c) k q-\frac{1}{2} k q^{2}[1+\alpha(k-1)]
$$

The question we intend to answer is which regime maximizes total surplus.

Figure 1 (below) displays the total surpluses as a function of $\alpha$ under the two-part tariff and the fixed-fee regimes when there is only one licensor $(\chi=1)$.

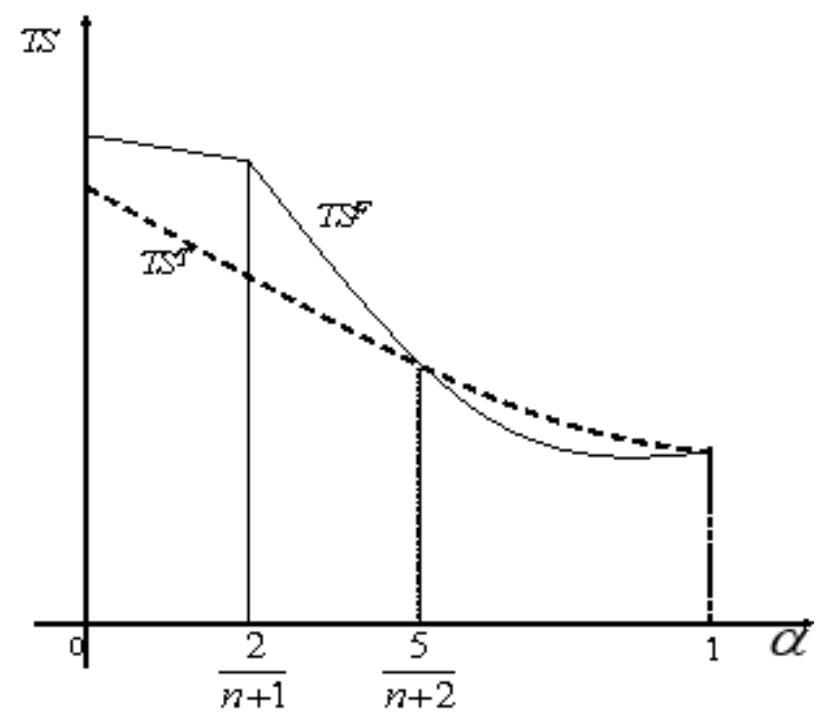

Figure 1: $T S^{F}$ and $T S^{T}$ with $\chi=1$. 
For $\chi=1$, the total surplus is maximized using the fixed-fee regime for $\alpha \in] 0, \frac{5}{n+2}\left[\right.$ and the two-part tariff for $\alpha \in\left[\frac{5}{n+2}, 1\right]$. The royalty regime is sub-optimal as it is always dominated by the two-part tariff regime. This result is very close to what we obtain in Proposition 5 and Lemma 4.

As a general rule, two-part tariff is the most appropriate way to combine the benefits of product variety and low prices when the number of potential entrants is large. ${ }^{10}$ It allows full entry of differentiated firms while avoiding price distortions, which also maximizes licensing profits and consumer surplus. This eventually changes as product differentiation increases and/or the number of potential entrants is low. In that case, the fixed-fee regime is a better way to obtain lower prices with a limited number of licensees.

We consider now the case $\chi \geq 2$. Proposition 7 gives a comparison of all the different regimes in terms of the surplus generated.

Proposition 7. For any $\chi \geq 2$, we establish the following:

(i) The two-part tariff regime leads to a higher total surplus than the royalty regime.

(ii) There exists a unique $\alpha^{T F} \in\left[\frac{2}{(2 \chi-1) n+1}, \frac{1}{\chi}\right]$ such that the fixed-fee regime maximizes the total surplus for all $\alpha \in\left[0, \alpha^{T F}\right]$.

(iii) For $\alpha \in\left[\alpha^{T F}, \frac{1}{\chi}\right]$ the two-part tariff regime maximizes the total surplus.

(iv) Finally, there exists $n_{\chi}$ the unique solution to (15) in Appendix, such that the fixed-fee regime is optimal for all $\alpha \in\left[\frac{1}{\chi}, 1\right]$ if $n \leq n_{\chi}$. And if $n>n_{\chi}$

\footnotetext{
${ }^{10}$ The greater the number of products downstream, the wider the range of $\alpha$ for which the two-part tariff regime maximizes the total surplus.
} 
there exists a unique $\widehat{\alpha}^{R F} \in\left[\frac{1}{\chi}, 1\right]$ such that the royalty regime is optimal over $\left[\frac{1}{\chi}, \widehat{\alpha}^{R F}\right]$ while the fixed-fee regime dominates for any $\alpha \in\left[\widehat{\alpha}^{R F}, 1\right]$.

Proof: See Appendix.

Figures 2 and 3 below illustrates Proposition 7 .



Figure 2: $T S^{F}, T S^{T}$ and $T S^{R}$ for any $\chi>1$ and $n \leq n_{\chi}$.

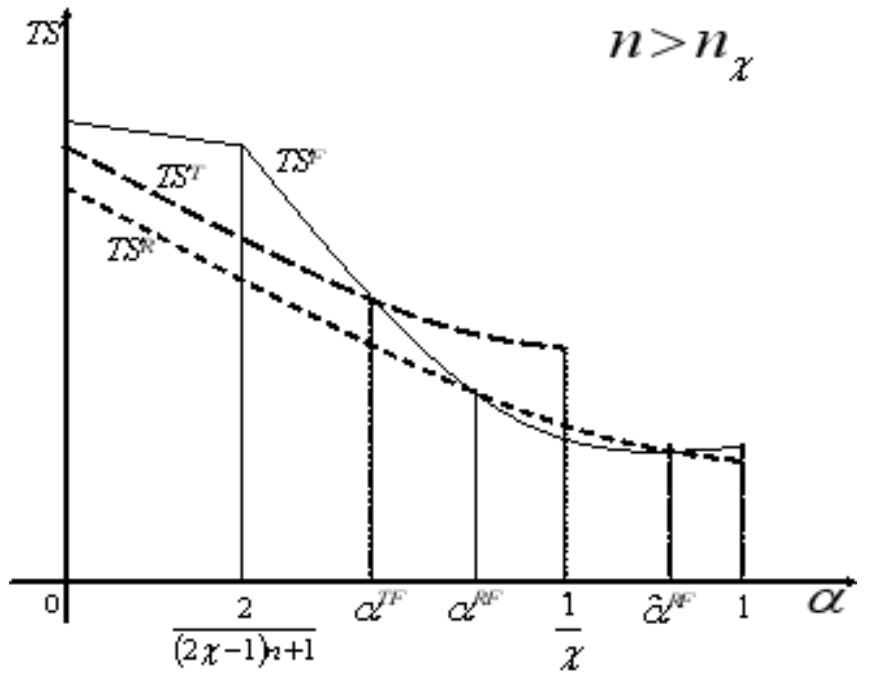


Figure 3: $T S^{F}, T S^{T}$ and $T S^{R}$ for any $\chi>1$ and $n>n_{\chi}$.

As with profit comparison, we can observe that any regime may maximize total surplus in the presence of a coordination failure by the licensors. The conditions for dominance of each regime are very similar to those displayed in

Proposition 5. For any $\alpha \in\left[0, \frac{1}{\chi}\right]$ the reason a regime is optimal is the same as that for the case of $\chi=1$. For $\alpha>\frac{1}{\chi}$, the only relevant regimes are the fixedfee and the royalty regimes. Therefore consumers either face a monopolistic supplier and no price distortion or $n$ suppliers (and thus $n$ varieties) and double marginalization. As we have seen, even when products are close substitutes $(\alpha=1)$ the monopolistic price with no royalty is lower than the price prevailing with $n$ entrants and a royalty regime.

Proposition 7 tells us that allowing for more varieties is best only when the number of potential varieties $(n)$ is large enough and products are sufficiently differentiated. More generally, it is trivial to prove that as $n$ increases, the intervals $\left[\alpha^{T F}, \frac{1}{\chi}\right]$ and $\left[\frac{1}{\chi}, \widehat{\alpha}^{R F}\right]$ become wider, since more varieties increases the total surplus under the royalty and two-part tariff regimes.

\section{Conclusion}

In this paper we have explored the licensing of complementary patents to manufacturers entering a new market for standard-compliant products. It is well known that the separate licensing of such patents entails a coordination failurenamely double marginalization-when licensors set per-unit royalties in a decen- 
tralized fashion. Considering the case of licensing regimes based on fixed-fees or two-part tariffs, we have characterized the licensing strategies of the patent owners depending on the degree of product differentiation, the number of potential entrants, and the number of patent owners. We have in particular established that each regime entails specific types of coordination failures when licensors are numerous and have compared the respective performances of the three regimes.

Each regime entails specific advantages for owners of patents that read on a standard. When discrimination is ruled out, fixed fees allow the control of licensee numbers by establishing, and raising if necessary, a fixed cost of entry in the market for standard compliant products. Moreover, they allow a full extraction of the industry profits. However, they cannot prevent licensees from competing away part of their profits. By contrast, per-unit royalties can neither limit entry nor extract full industry profits, but they do allow the licensor to raise marginal costs, thereby mitigating price competition. We have shown that per-unit royalties are therefore preferable for the licensors in specific cases where a large number of licensees would manufacture sufficiently differentiated products, since product variety allows greater profit. Since the two-part tariff regime combines both royalties and fixed-fees, when there is only one licensor this regime is better than the two other regimes in terms of licensing profits. The single licensor can afford to allow full entry, thereby maximizing variety, while using royalties to control prices and, finally, fixed fees to extract all profits.

As the number of licensors increases we reach the following results. Like pure royalties, the fixed-fee and two-part tariff regimes generate a coordina- 
tion failure, although of a different type. Under the fixed-fee regime, licensors tend to demand excessive fees, the stacking of which results in an inefficiently small number of licensees. Two-part tariffs raise the same problem of fixed-fee stacking when products are weakly differentiated. As products become more differentiated, the licensing equilibrium eventually changes, which modifies the nature of the coordination failure. In that case all candidates are granted a license, but the stacking of royalties now induces the same type of inefficiency as in a pure royalty regime. In any case, total licensing profit decreases as the number of patent owners increases.

Comparing the three regimes shows that each of them may maximize the total licensing revenue when several patents must be licensed. The fixed-fee regime dominates when products are weakly differentiated, since there is then no advantage in letting a large number of licensees enter the market. When products are strongly differentiated, two-part tariff is the best regime, provided the number of potential entrants is sufficiently large. It allows full entry, thereby maximizing variety, while inducing fewer price distortions than pure royalties. Finally, pure royalty may dominate when products are mildly differentiated and potentially numerous. Licensors would then indeed opt for a fixed-fee regime rather than two-part tariff, thereby precluding entry and losing the benefit of product variety. A welfare comparison including patent owners and consumers does not significantly change these results. This suggests that letting the patent owners' choose a particular licensing regime is socially acceptable.

This analysis has limitations that would be worth addressing in follow-up 
research. A first possible extension concerns the nature of the licensed innovation. By focusing on a standard whose adoption allows entry into a new market, we have implicitly likened it to a drastic innovation. Although this assumption is quite reasonable, it could be relaxed by considering an innovation that is not drastic, to have a better understanding, for instance, of the transition between two generations of standards. While most debates on the decentralized licensing of complementary patents focus on cooperative industry standards, the analysis could be extended to more general cases where licensors are not constrained by any collective rule. Such an analysis would make it possible to account for the possibility that patent owners individually choose their licensing scheme, as well as for possible competition between some patent owners. 


\section{Appendix}

\section{Proof of proposition 2.}

Let $L=\sum_{s=1}^{\chi} l_{s}$ denote the sum of fixed-fees. Under free entry, the number of firms participating in the downstream market is given by:

$$
k(L)=\left\{\begin{array}{l}
0 \text { if } L>\left(\frac{a-c}{2}\right)^{2} \\
1 \text { if } L=\left(\frac{a-c}{2}\right)^{2} \\
\frac{a-c-(2-\alpha) \sqrt{L}}{\alpha \sqrt{L}} \text { if } L \in\left[\left(\frac{a-c}{2}\right)^{2},\left(\frac{a-c}{2+\alpha(n-1)}\right)^{2}\right] \\
n \text { if } L \leq\left[\frac{a-c}{2+\alpha(n-1)}\right]^{2}
\end{array}\right.
$$

We consider successively the corner solutions and then the interior solution.

- Corner solution 1: $k(L)=1$.

Assume that patent owners $2,3, . ., \chi$ set $l=\frac{1}{\chi} \pi(1,0)=\frac{1}{\chi}\left(\frac{a-c}{2}\right)^{2}$ and let us examine when it is optimal for patent owner 1 to set the same fixed-fee. In that case $L_{-1}=\sum_{s=2}^{\chi} l_{s}=\frac{\chi-1}{\chi} \pi(1,0)$. Taking $L_{-1}$ as given patent holder 1 maximizes

$$
\begin{gathered}
\operatorname{Max}_{k} \Pi(k) \\
\Pi(k)=k\left[\pi(k, 0)-L_{-1}\right]
\end{gathered}
$$

We have

$$
\begin{gathered}
\frac{d \Pi}{d k}=\pi(k, 0)-L_{-1}+k \frac{d \pi}{d k} \\
\Leftrightarrow \frac{d \Pi}{d k}=\left[\frac{a-c}{2+\alpha(k-1)}\right]^{2}\left[1-\frac{2 k \alpha}{2+\alpha(k-1)}\right]-\frac{\chi-1}{\chi}\left(\frac{a-c}{2}\right)^{2} .
\end{gathered}
$$


Evaluating the above at $k=1$ we get:

$$
\left.\frac{d \Pi}{d k}\right|_{k=1}=\frac{(a-c)^{2}}{4}\left[\frac{1}{\chi}-\alpha\right]
$$

It can be verified that $\Pi(k)$ is concave. Thus for $\alpha \geq \frac{1}{\chi}$ the above derivative is negative and it establishes that $\Pi(k)$ reaches a maximum at $k=1$ meaning that patent holder 1 has no incentive to increase entry and sets $l_{1}=\frac{1}{\chi} \pi(1,0)$. Given that the argument would be perfectly symmetric for patent holder $2,3, \ldots$ and $\chi$, we have established that setting $L=\left(\frac{a-c}{2}\right)^{2}$ and selling $k=1$ license forms a Nash equilibrium for any $\alpha \geq \frac{1}{\chi}$.

- Corner solution 2: $k(L)=n$.

Assume that patent owners $2,3, . ., \chi$ set $l=\frac{1}{\chi} \pi(n, 0)=\frac{1}{\chi}\left[\frac{a-c}{2+\alpha(n-1)}\right]^{2}$ and let us examine when it is optimal for patent owner 1 to set the same fixedfee. In that case we have $L_{-1}=\frac{\chi-1}{\chi} \pi(n, 0)$. At $L=L_{-1}, n$ firms enter. Patent holder 1 will obviously set $l_{1} \geq \frac{\pi(n, 0)}{\chi}$ as anything below would only lower her profit. Patent holder 1 maximizes

$$
\begin{gathered}
\operatorname{Max}_{k} \Pi(k) \\
\Pi(k)=k\left[\pi(k, 0)-L_{-1}\right]
\end{gathered}
$$

We have

$$
\frac{d \Pi}{d k}=\pi(k, 0)-L_{-1}+k \frac{d \pi}{d k}
$$


$\Leftrightarrow \frac{d \Pi}{d k}=\left[\frac{a-c}{2+\alpha(k-1)}\right]^{2}\left[1-\frac{2 k \alpha}{2+\alpha(k-1)}\right]-\frac{\chi-1}{\chi}\left(\frac{a-c}{2+\alpha(n-1)}\right)^{2}$.

Evaluating the above at $k=n$ we have:

$$
\left.\frac{d \Pi}{d k}\right|_{k=n}=\frac{(a-c)^{2}}{\chi(2+\alpha(n-1))^{3}}[2-\alpha(1+n(2 \chi-1))] .
$$

The above derivative is positive for any $\alpha \leq \frac{2}{(2 \chi-1) n+1}$. Therefore, since $\Pi(k)$ is concave, it establishes that $\Pi(k)$ reaches a maximum at $k=n$ for such values of $\alpha$. Given that the argument would be perfectly symmetric for patent holder $2,3, \ldots$ and $\chi$, we have established that setting $L=$ $\left[\frac{a-c}{2+\alpha(n-1)}\right]^{2}$ and selling $k=n$ licenses forms a Nash equilibrium for any $\alpha \leq \frac{2}{(2 \chi-1) n+1}$.

- Interior solution.

Assume that there exists an equilibrium such that $L$ belongs to $\left[\left(\frac{a-c}{2}\right)^{2},\left(\frac{a-c}{2+\alpha(n-1)}\right)^{2}\right]$. Taking as given the fixed-fees fixed by other patent owners, patent holder $s$ solves:

$$
\operatorname{maxk}_{l_{s}}(L) l_{s}
$$

The first order condition (hereafter FOC) leads to:

$$
l_{s}^{*}=-\frac{k(L)}{k^{\prime}(L)}>0
$$

This clearly implies that all patent owners set the same royalty at equilibrium: 
$l^{*}=-\frac{k(L)}{k^{\prime}(L)}$. As there are $\chi$ patent owners, we have:

$$
L^{*}=\chi l^{*}=-\chi \frac{k(L)}{k^{\prime}(L)}
$$

Developing and solving for $L$ then yields:

$$
L^{*}=\left(\frac{2 \chi-1}{2 \chi}\right)^{2}\left(\frac{a-c}{2-\alpha}\right)^{2}
$$

As argued above, we have $\left.k^{*} \in\right] 1, n[$ if and only if

$$
\left[\frac{a-c}{2+\alpha(n-1)}\right]^{2} \leq L^{*} \leq\left(\frac{a-c}{2}\right)^{2}
$$

Using the expression of $L^{*}$ in (7) we can write:

$$
L^{*} \leq\left(\frac{a-c}{2}\right)^{2} \Leftrightarrow \alpha \leq \frac{1}{\chi}
$$

and

$$
L^{*} \geq\left[\frac{a-c}{2+\alpha(n-1)}\right]^{2} \Leftrightarrow \alpha \geq \frac{2}{(2 \chi-1) n+1}
$$

Hence $\left.k^{*} \in\right] 1, n[$ if and only if

$$
\frac{2}{(2 \chi-1) n+1} \leq \alpha \leq \frac{1}{\chi}
$$

which forms a non-empty interval, and shows that the Nash equilibria we have found are continuous in $\alpha$. 
It can be checked that the first term on the right hand side is increasing in $\chi$ from $\frac{1}{4}$ to 1 . Hence the cumulative fixed-fee is increasing in the number of licensors.

\section{Proof of proposition 3.}

- First we show that the proposed fixed-fees and royalties form a symmetric Nash equilibrium.

-For all $\alpha \leq \frac{1}{\chi}$ we have

$$
l^{*}=\frac{1}{\chi}\left(\frac{a-c}{2+\alpha(n-1)(\chi+1)}\right)^{2} \text { and } r^{*}=\frac{\alpha(n-1)(a-c)}{2+\alpha(n-1)(\chi+1)} .
$$

and

$$
k\left(l^{*}, r^{*}\right)=n
$$

-For all $\left.\alpha \in] \frac{1}{\chi}, 1\right]$ we have $r^{*}=0$ and $l^{*}=\frac{(a-c)^{2}}{4 \chi}$ and $k\left(L^{*}, R^{*}\right)=1$.

Assume $(\chi-1)$ patent owners apply the fixed-fee an royalty described above.

The remaining patent owner solves ${ }^{11}$

$$
\operatorname{Max}_{k, r_{s}} \pi_{s}\left(k, r_{s}\right)
$$

where $\pi_{s}\left(k, r_{s}\right)=k\left[l_{s}+r_{s} q\left(r_{s}, k\right)\right]$

with

$$
l_{s}=\max \left\{\left(\frac{a-c-r_{s}-R_{-s}^{*}}{2+\alpha(k-1)}\right)^{2}-F(x), 0\right\}
$$

\footnotetext{
${ }^{11}$ Maximizing with respect to $l$ or $k$ leads to the same outcome.
} 
where

$$
R_{-s}^{*}=\left\{\begin{array}{l}
\frac{(\chi-1) \alpha(n-1)(a-c)}{2+\alpha(n-1)(\chi+1)} \text { if } \alpha \leq \frac{1}{\chi}, \\
0 \text { otherwise, }
\end{array}\right.
$$

and

$$
F(x)=\frac{\chi-1}{\chi}\left(\frac{a-c}{2+\alpha(x-1)(1+\chi)}\right)^{2}
$$

with $x=n$ for all $\alpha \leq \frac{1}{\chi}$ and $x=1$ for $\alpha>\frac{1}{\chi}$. (Note that the above is independent of $k$ and $r_{s}$. However because it is multiplied by $k$ it will appear in the FOC.)

The $F O C$ with respect to $r_{s}$ leads to

$$
a-c-r_{s}-R_{-s}^{*}=r_{s}+2 q\left(r_{s}, R_{-s}^{*}, k\right)
$$

Substituting in $k^{*}$ and $R_{-s}^{*}$ and $r_{s}=r^{*}$ we find that the above is indeed equal to zero. Concavity can be easily checked. Thus the royalty $r^{*}$ forms a Nash equilibrium.

We now turn to the optimal value for $k^{*}$. Differentiating the profit with respect to $k$ leads to

$$
\begin{aligned}
\frac{\partial \pi_{s}}{\partial k}= & q^{2}\left(k, r_{s}, R_{-s}^{*}\right)-F(x)-2 \alpha k q^{2}\left(k, r_{s}, R_{-s}^{*}\right) \frac{1}{2+\alpha(k-1)} \\
& +r_{s} q\left(k, r_{s}, R_{-s}^{*}\right)-\frac{k \alpha r_{s}}{2+\alpha(k-1)} q\left(k, r_{s}, R_{-s}^{*}\right)
\end{aligned}
$$


Moreover we have ${ }^{12}$

$$
\frac{\partial^{2} \pi_{s}}{\partial k^{2}}=-\frac{2 \alpha q^{2}}{(2+\alpha(k-1))^{2}}\left[\alpha k(1-\alpha)+(2-\alpha)^{2}\right]<0 .
$$

Thus the profit function is concave in $k$.

It is a best response for the remaining firm to set $l=l^{*}$ and thus allow the entry of $n$ firms if and only if

$$
\left.\frac{\partial \pi_{s}}{\partial k}\right|_{k=n} \geq 0
$$

We have

$$
\left.\frac{\partial \pi_{s}}{\partial k}\right|_{k=n}=\left[\frac{(a-c)}{2+\alpha(n-1)(1+\chi)}\right]^{2}\left[\frac{1}{\chi}-\alpha\right],
$$

therefore $\left.\frac{\partial \pi_{s}}{\partial k}\right|_{k=n} \geq 0$ when $\alpha \leq \frac{1}{\chi}$.

It is a best response for the remaining firm to set $l=l^{*}\left(\right.$ and $\left.r^{*}=0\right)$ and thus allow the entry of 1 firm if and only if

$$
\left.\frac{\partial \pi_{s}}{\partial k}\right|_{k=1} \leq 0
$$

We have

$$
\left.\frac{\partial \pi_{s}}{\partial k}\right|_{k=1}=\frac{(a-c)^{2}}{4}\left[\frac{1}{\chi}-\alpha\right]
$$

therefore $\left.\frac{\partial \pi_{s}}{\partial k}\right|_{k=1} \leq 0$ when $\alpha>\frac{1}{\chi}$.

- Second we demonstrate how we found the values for $l^{*}$ and $r^{*}$.

${ }^{12}$ After inserting $r^{*}=\alpha(k-1) q($ see below). 
Taking as given the fixed-fee and royalty set by other patent owners, licensor $s$ solves

$$
\operatorname{Max}_{l_{s}, r_{s}} k\left[l_{s}+r_{s} q\left(r_{s}, k\right)\right]
$$

subject to

$$
k=\min \{\widehat{k}, n\} \text { with } \pi(\widehat{k}, r)=\sum_{j=1, \ldots, \chi} l_{j} .
$$

For any given pairs $\left(r_{j}, l_{j}\right)_{j=1, \ldots, \chi}$ the variable $\widehat{k}$ is uniquely defined. Let $R=\left(r_{1}, \ldots, r_{\chi}\right)$ and $L=\left(l_{1}, \ldots, l_{\chi}\right)$. The Lagrangian associated with this maximization problem is given by

$$
L(k, r)=k(R, L)\left[l_{s}+r_{s} q(R, k(R, L))\right]-\lambda_{s}[k(R, L)-n] .
$$

The reaction functions are determined as follows:

-The derivative with respect to $r_{s}, \frac{\partial L}{\partial r_{s}}$, must equal zero:

$$
\frac{\partial k}{\partial r_{s}}\left[l_{s}+r_{s} q\right]+k\left[q+r_{s}\left(\frac{\partial q}{\partial k} \frac{\partial k}{\partial r_{s}}+\frac{\partial q}{\partial r_{s}}\right)\right]=\lambda_{s} \frac{\partial k}{\partial r_{s}}
$$

Note that $\pi=q^{2}$ thus the fixed-fees are such that

$$
q^{2}(k(R, L), R)-L=0
$$

Differentiating the above with respect to $r_{s}$ leads to

$$
2 q\left(\frac{\partial q}{\partial k} \frac{\partial k}{\partial r_{s}}+\frac{\partial q}{\partial r_{s}}\right)=0
$$


therefore the expression $\left(\frac{\partial q}{\partial k} \frac{\partial k}{\partial r_{s}}+\frac{\partial q}{\partial r_{s}}\right)$ in (8) is equal to 0 .

Finally $\frac{\partial k}{\partial r_{s}}=-\frac{\frac{\partial q}{\partial r_{s}}}{\frac{\partial q}{\partial k}}=-\frac{1}{\alpha q}$ after simplifications. Thus (8) reads

$$
l_{s}+r_{s} q-\alpha k q^{2}=\lambda_{s}
$$

-The derivative with respect to $l_{s}, \frac{\partial L}{\partial l_{s}}$, must equal zero:

$$
\frac{\partial k}{\partial l_{s}}\left[l_{s}+r_{s} q\right]+k\left[1+r_{s} \frac{\partial q}{\partial k} \frac{\partial k}{\partial l_{s}}\right]=\lambda_{s} \frac{\partial k}{\partial l_{s}}
$$

Using (9) we have

$$
\frac{\partial q}{\partial k} \frac{\partial k}{\partial l_{s}}=\frac{1}{2 q}
$$

Moreover

$$
\frac{\partial k}{\partial l_{s}}=-\frac{(2+\alpha(k-1))}{2 \alpha q^{2}}
$$

Plugging the above in (11) we get

$$
\lambda_{s}=l_{s}+r_{s} q-\alpha k q \frac{2 q+r_{s}}{2+\alpha(k-1)} .
$$

Whether or not $\lambda_{s}=0$ we must always have

$$
\alpha k q^{2}=\alpha k q \frac{2 q+r_{s}}{2+\alpha(k-1)} .
$$


From there we obtain that

$$
r_{s}=\alpha(k-1) q(R, k)
$$

Solving the above for $r$ shows that in a symmetric equilibrium we necessarily have

$$
r^{T}=\alpha(k-1) \frac{a-c-\chi r^{T}}{2+\alpha(k-1)}
$$

which is the value of $r^{T}$ in proposition 3 .

Consider now (10). It can be re-written as

$$
\chi l_{s}+\chi r^{T} q\left(R^{T}, k\right)-\chi \alpha k q^{2}\left(R^{T}, k\right)-\chi \lambda_{s}=0 .
$$

In a symmetric equilibrium we have $\chi l^{T}=q^{2}\left(R^{T}, k\right)$ due to the full extraction of the surplus. Using this and the value for $r^{T}$ the above re-writes as

$$
\frac{a-c}{2+\alpha(k-1)(\chi+1)}[1-\alpha \chi]-\chi \lambda_{s}=0
$$

We must have $\lambda_{s} \geq 0$ at the solution. Thus either

$$
1-\alpha \chi>0 \text { and thus } \lambda_{s} \neq 0 \text { so that } k=n \text { at the solution. }
$$

Or else $1-\alpha \chi<0$ and thus $\lambda_{s}=0$ so that $k<n$. In this case note that the function we maximize is monotone in $l$ and reaches a maximum for $l$ such that $k=1$. 


\section{Proof of Lemma 3}

Assume that there exist an equilibrium with a positive royalty $\left(r^{*}\right)$ and a positive fixed fee $\left(l^{*}\right)$ such that $\left.k^{*} \in\right] 1, n[$ firms enter. If such an equilibrium exists then $r^{*}$ and $k^{*}$ solve

$$
\underset{r, k}{\operatorname{Maxk}}[l(k)+r q(r, k)]
$$

where,

$$
l(k)+(\chi-1) l^{*}=\pi(k, r)=q^{2}(k, r) .
$$

Taking the first order conditions with respect to $r$ shows that setting

$$
r^{*}=\frac{\alpha(k-1)(a-c)}{2+\alpha(k-1)(1+\chi)}
$$

is optimal. Note that this means that $r^{*}=0$ is indeed optimal for the specific case $k=1$. When differentiating with respect to $k$ we get

$$
\frac{\partial \Pi^{T}}{\partial k}=l(k)+r q(k, r)+k \frac{\partial q}{\partial k}[2 q(k, r)+r] .
$$

In equilibrium we have $\chi l\left(k^{*}\right)=q^{2}\left(k^{*}, r^{*}\right), r^{*}=\alpha\left(k^{*}-1\right) q\left(k^{*}, r^{*}\right)$ and

$$
\frac{\partial q}{\partial k}=-\frac{\alpha}{2+\alpha(k-1)} q\left(k^{*}, r^{*}\right) .
$$

Therefore the derivative of the licensor's profit with respect to $k$ can be re- 
written as

$$
\frac{\partial \Pi^{T}}{\partial k}=q^{2}\left(k^{*}, r^{*}\right)\left[\frac{1}{\chi}-\alpha\right] .
$$

Therefore $\frac{\partial \Pi^{T}}{\partial k} \geq 0$ if and only if $\chi \leq \frac{1}{\alpha}$.

\section{Proof of Proposition 4}

In equilibrium, we have:

$$
\Pi^{F}=k^{F}\left[\frac{(a-c)}{\left(2+\alpha\left(k^{*}-1\right)\right)}\right]^{2},
$$

where $k^{F}=\min \left\{\frac{2-\alpha}{\alpha}, n\right\}$, and

$$
\Pi^{R}=\frac{1}{4} n \frac{(a-c)^{2}}{(2+\alpha(n-1))} .
$$

When $\alpha \leq \frac{2}{n+1}$, we have $k^{F}=n$ and for all such cases

$$
\Pi^{F}>\Pi^{R} \Leftrightarrow \alpha<\frac{2}{n-1}
$$

which is systematically true.

When $\alpha>\frac{2}{n+1}$, we have $k^{F}=\frac{2-\alpha}{\alpha}$ and for all such cases

$$
\Pi^{F}>\Pi^{R} \Leftrightarrow n<\frac{2-\alpha}{\alpha(1-\alpha)}
$$

The above holds provided $n \geq 6$ and $\alpha \in[\underline{\alpha}, \bar{\alpha}]$ as stated in proposition 4 .

\section{Proof of proposition 5}


Point 1 is obvious. Regarding point 2: showing that two-part tariff yields a greater income than the other 2 regimes is obvious. As for the comparison between the fixed-fee and the royalty regimes, we have $\chi \Pi^{F} \geq \chi \Pi^{R}$ if and only if

$$
(2 \chi-1)(1+\chi)(2+\alpha(n-1))>4 \alpha \chi^{3}(2-\alpha) n .
$$

Figure 4 (below) represents the left and right hand sides of the inequality above, with $n$ on the horizontal axis.

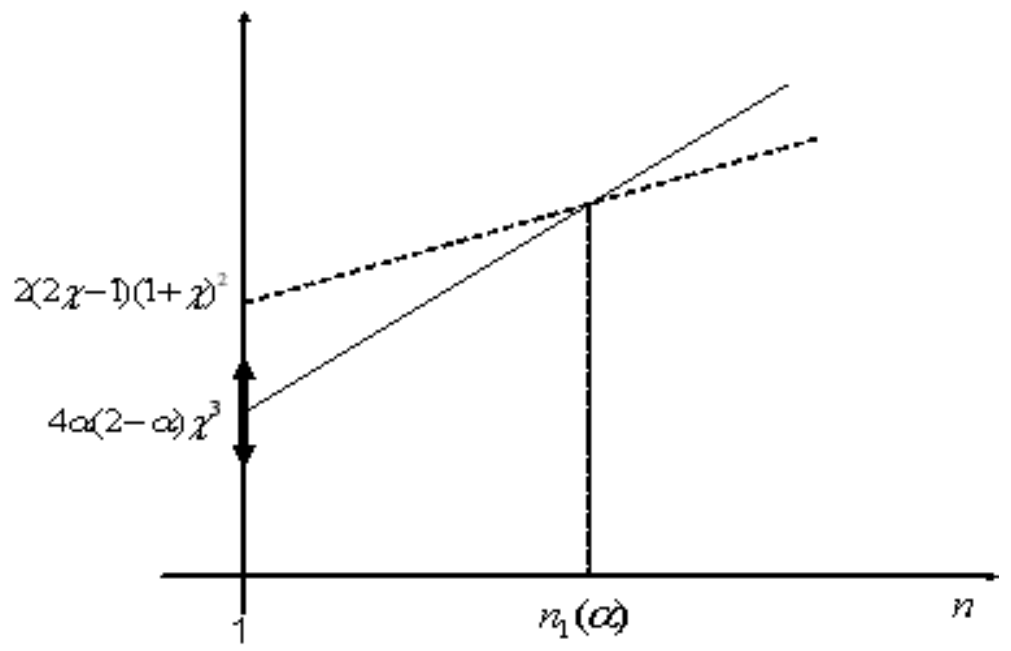

Figure 4: Representing the left and right had sides of (12).

For any $\left.\alpha \in] \frac{2}{(2 \chi-1) n+1}, \frac{1}{\chi}\right]$, we have

$$
4 \alpha(2-\alpha) \chi^{3}<2(2 \chi-1)(1+\chi)^{2} .
$$


Moreover, for any $\left.\alpha \in] \frac{2}{(2 \chi-1) n+1}, \frac{1}{\chi}\right]$,

$$
\alpha(2 \chi-1)(1+\chi)<4 \alpha(2-\alpha) \chi^{3}
$$

Therefore, as a functions of $n$, the right hand side of inequality (12) is lower than the left hand side but it is also steeper. Thus, the two curves cross at most once for $n$ sufficiently large.

Finally, we turn to point 3 . We have $\chi \Pi^{F} \geq \chi \Pi^{R}$ if and only if

$$
(2+\alpha(n-1))(1+\chi)^{2}>4 \chi n
$$

Figure 5 (below) represents the left and right hand sides of the inequality above, with $n$ on the horizontal axis.

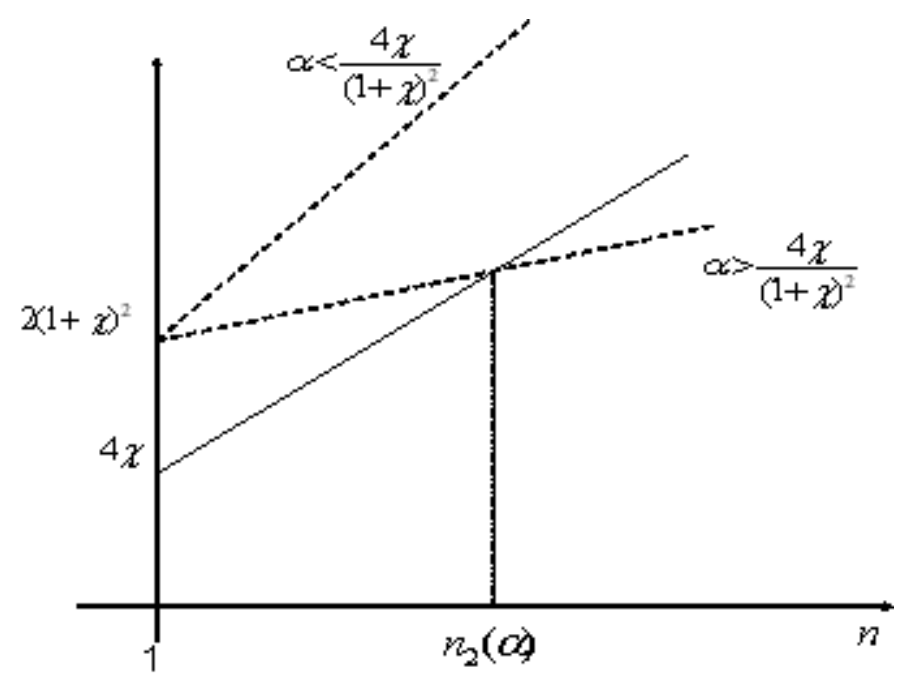

Figure 5: Illustrating (13). 
We have

$$
2(1+\chi)^{2}>4 \chi
$$

Moreover, the slopes of the left and right hand side functions of $n$ are equal if and only if

$$
\left.\left.\alpha=\frac{4 \chi}{(1+\chi)^{2}}, \text { which belongs to }\right] \frac{1}{\chi}, 1\right] \text {. }
$$

If $\alpha \geq \frac{4 \chi}{(1+\chi)^{2}}$ the two curves never cross. If $\alpha<\frac{4 \chi}{(1+\chi)^{2}}$ there exists a unique $n_{2}$ such that $\chi \Pi^{F} \geq \chi \Pi^{R}$ if and only if $n>n_{2}$.

\section{Proof of proposition 6}

The comparison of $k^{R}, k^{F}$ and $k^{T}$ is obvious. To compare the prices downstream, note that the price cost margins are given by the following expressions:

$$
\begin{gathered}
p^{F}-c=\frac{a-c}{2+\alpha\left(k^{F}-1\right)}, \\
p^{R}-c=\left(\frac{a-c}{1+\chi}\right) \frac{1+2 \chi+\alpha \chi(n-1)}{2+\alpha(n-1)},
\end{gathered}
$$

and

$$
p^{T}-c=\frac{(a-c)(1+\alpha \chi(n-1))}{2+\alpha(n-1)(1+\chi)} \text { where } \alpha \leq \frac{1}{\chi} .
$$

\section{Proof of Proposition 7}

Note that the total surplus is concave in $q$ and maximizes at $q^{*}=\frac{a-c}{1+\alpha(k-1)}$. Due to concavity, for a given $k$, the total surplus increases in $q$ for and $q<q^{*}$.

- Consider any $\alpha \leq \frac{2}{(2 \chi-1) n+1}$. 
All regimes have $k=n$. We have

$$
\begin{gathered}
q^{R}=\left(\frac{1}{1+\chi}\right)\left(\frac{a-c}{2+\alpha(n-1)}\right), \\
q^{F}=\frac{(a-c)}{2+\alpha(n-1)}
\end{gathered}
$$

and

$$
q^{T}=\frac{a-c}{2+\alpha(n-1)(1+\chi)}
$$

It is trivial to show that $q^{R}<q^{T}<q^{F}<q^{*}$. Given that surplus increases in $q$ for any $q<q^{*}$, we have $T S^{R}<T S^{T}<T S^{F}$.

- Consider any $\alpha>\frac{1}{\chi}$. Over that interval the only two relevant regimes are the fixed fee regime and the royalty regime. We have

$$
T S^{F}=\frac{3}{8}(a-c)^{2}
$$

and

$$
T S^{R}=\frac{n[3+4 \chi+\alpha(n-1)(1+2 \chi)]}{2(1+\chi)^{2}(2+\alpha(n-1))^{2}}(a-c)^{2} .
$$

Note that $T S^{R}$ is decreasing in $\alpha$ and increasing in $n$ for any given $\alpha$. Note also that $T S^{F}$ is constant in both $\alpha$ and $n$. We have $T S^{R}>T S^{F}$ at $\alpha=\frac{1}{\chi}$ if and only if $n>n_{\chi}$ which solves

$$
4 n \chi[\chi(3+4 \chi)+(n-1)(1+2 \chi)]=3(1+\chi)^{2}[2 \chi-1+n]^{2} .
$$


Since $\operatorname{Lim}_{n \rightarrow+\infty} T S^{R}=\frac{(1+2 \chi)(a-c)^{2}}{2 \alpha(1+\chi)^{2}}$, we have that for any $\frac{4(1+2 \chi)}{3(1+\chi)^{2}}<$ $\alpha<1: T S^{F}>T S^{R}$.

Therefore for any $n \leq n_{\chi}$ we have $T S^{R}<T S^{F}$ for all $\alpha>\frac{1}{\chi}$ since $T S^{R}$ decreases in $\alpha$ and is below $T S^{F}$ at $\alpha=\frac{1}{\chi}$. And for $n>n_{\chi}$ there exists a unique $\widehat{\alpha}^{R F} \in\left[\frac{1}{\chi}, \frac{4(1+2 \chi)}{3(1+\chi)^{2}}\right]$ such that $T S^{R} \geq T S^{F}$ if and only if $\alpha \in\left[\frac{1}{\chi}, \widehat{\alpha}^{R F}\right]$ since $T S^{R}$ decreases in $\alpha$ but is above $T S^{F}$ at $\alpha=\frac{1}{\chi}$ and below $T S^{F}$ at $\alpha=\frac{4(1+2 \chi)}{3(1+\chi)^{2}}$.

- Finally, let us consider any $\alpha \in\left[\frac{2}{(2 \chi-1) n+1}, \frac{1}{\chi}\right]$.

The comparison of the two-part tariff and the royalty regime leads to $T S^{T}>T S^{R}$ since we still have $k^{R}=k^{T}=n$ and $q^{R}<q^{T}<q^{*}$.

Comparing the two-part tariff regime with the fixed fee regime:

Over the interval considered, we have

$$
T S^{F}=\frac{[2 \chi(3-\alpha)-1]}{8 \chi^{2} \alpha(2-\alpha)}(a-c)^{2}
$$

and

$$
T S^{T}=\frac{n}{2} \frac{[3+\alpha(n-1)(1+2 \chi)]}{[2+\alpha(n-1)(1+\chi)]^{2}}(a-c)^{2} .
$$

Both total surpluses are decreasing in $\alpha$. We know that $T S^{F}>T S^{T}$ at $\alpha=\frac{2}{(2 \chi-1) n+1}$ and one can easily show that $T S^{F}<T S^{T}$ at $\alpha=\frac{1}{\chi} .{ }^{13}$

Given that the functions $T S^{F}$ and $T S^{T}$ are continuous in $\alpha$, it must be

\footnotetext{
${ }^{13}$ Indeed $T S^{T}>T S^{F}$ at $\alpha=\frac{1}{\chi}$ is equivalent to $(\chi-1)[(5 n+3) \chi+3(n-1)]>0$ which is always true.
} 
that $T S^{F}$ and $T S^{T}$ cross at least once, and, if more than once, they should cross an odd number of times. We now prove that they can only cross once.

Setting $T S^{T}=T S^{F}$ is equivalent to requiring ${ }^{14}$

$$
F(\alpha)=0
$$

where

$$
F(\alpha)=4(6 \chi-1)+\lambda_{3} \alpha^{3}+\lambda_{2} \alpha^{2}+\lambda_{1} \alpha,
$$

with

$$
\begin{gathered}
\lambda_{3}=2 \chi(n-1)\left[n\left(3 \chi^{2}-1\right)+(1+\chi)^{2}\right], \\
\lambda_{2}=(6 \chi-1)(n-1)^{2}(1+\chi)^{2}-8 \chi(n-1)(1+\chi) \\
\quad+12 n \chi^{2}-8 \chi^{2} n(n-1)(1+2 \chi),
\end{gathered}
$$

and

$$
\lambda_{1}=4(n-1)(5 \chi-1)-8 \chi(1+3 \chi) .
$$

The equation (18) admits 3 real solutions. We know that one is necessarily between $\left[\frac{2}{(2 \chi-1) n+1}, \frac{1}{\chi}\right]$ since $T S^{F}$ and $T S^{T}$ cross at least once over that interval. We show that the other 2 solutions are outside this interval. Since $\lambda_{3}>0, \lim _{\alpha \rightarrow+\infty} F(\alpha)=+\infty$. Since we know that $F\left(\frac{1}{\chi}\right)<0$, there exists $\alpha^{\prime}>\frac{1}{\chi}$ such that $F\left(\alpha^{\prime}\right)=0$. Since $\lambda_{3}>0, \lim _{\alpha \rightarrow-\infty} F(\alpha)=-\infty$.

\footnotetext{
${ }^{14}$ And we have $T S^{T}>T S^{F} \Leftrightarrow F(\alpha)<0$.
} 
However since $F(0)>0$, there exists $\alpha^{\prime \prime}<0$ such that $F\left(\alpha^{\prime \prime}\right)=0$. Thus there exists a unique $\alpha^{T F} \in\left[\frac{2}{(2 \chi-1) n+1}, \frac{1}{\chi}\right]$ such that $T S^{F}=T S^{T}$ and we have $T S^{T}>T S^{F}$ for any $\alpha \in\left[\alpha^{T F}, \frac{1}{\chi}\right]$.

\section{Comparing the royalty regime with the fixed fee regime:}

$T S^{R}$ is given by (14) and $T S^{F}$ is given by (16). Both total surpluses are decreasing in $\alpha$. We have $T S^{F}>T S^{R}$ at $\alpha=\frac{2}{(2 \chi-1) n+1}$. We have $T S^{F}<T S^{R}$ at $\alpha=\frac{1}{\chi}$ if and only if $n>n_{\chi}$, where $n_{\chi}$ solves (15). Following an argument similar to the one above we establish that if $T S^{R}$ and $T S^{F}$ cross over the interval considered for $\alpha$, then they can only cross once.

Setting $T S^{T}=T S^{F}$ is equivalent to requiring ${ }^{15}$

$$
G(\alpha)=0
$$

where

$$
G(\alpha)=4(6 \chi-1)(1+\chi)^{2}+\gamma_{3} \alpha^{3}+\gamma_{2} \alpha^{2}+\gamma_{1} \alpha,
$$

with

$$
\begin{gathered}
\gamma_{3}=\lambda_{3}, \\
\gamma_{2}=(6 \chi-1)(n-1)^{2}(1+\chi)^{2}-8 \chi(n-1)(1+\chi)^{2} \\
-8 \chi^{2} n(n-1)(1+2 \chi)+4 \chi^{2}(3+4 \chi) n,
\end{gathered}
$$

${ }^{15}$ And we have $T S^{R}>T S^{F} \Leftrightarrow G(\alpha)<0$. 
and

$$
\gamma_{1}=4(n-1)(6 \chi-1)(1+\chi)^{2}-8 \chi(1+\chi)^{2}-8 \chi^{2}(3+4 \chi) n .
$$

The equation (19) admits 3 real solutions. We show that at least 2 are outside the interval $\left[\frac{2}{(2 \chi-1) n+1}, \frac{1}{\chi}\right]$.

Since $\gamma_{3}>0, \lim _{\alpha \rightarrow-\infty} G(\alpha)=-\infty$. However since $G(0)>0$, there exists $\alpha^{*}<0$ such that $G\left(\alpha^{*}\right)=0$. For any $n>n_{\chi}$ we have $G\left(\frac{1}{\chi}\right)<$ 0 and since $\lim _{\alpha \rightarrow+\infty} G(\alpha)=+\infty$.there exists one $\alpha^{* *}>\frac{1}{\chi}$ such that $G\left(\alpha^{* *}\right)=0$. This proves that for any $n>n_{\chi}$ there exists a unique $\alpha^{R F} \in$ $\left[\frac{2}{(2 \chi-1) n+1}, \frac{1}{\chi}\right]$ such that $T S^{F}=T S^{R}$ and we have $T S^{R}>T S^{F}$ for any $\alpha \in\left[\alpha^{R F}, \frac{1}{\chi}\right]$. Note that at $n=n_{\chi}$ we have $\alpha^{R F}=\frac{1}{\chi}$ and $T S^{F}>T S^{R}$ for any $\alpha \in\left[\frac{2}{(2 \chi-1) n+1}, \frac{1}{\chi}\left[\right.\right.$. As $n$ decreases below $n_{\chi}$, $T S^{R}$ decreases and therefore it will necessarily be lower than $T S^{F}$ for all $\alpha \in\left[\frac{2}{(2 \chi-1) n+1}, \frac{1}{\chi}\right]$.

Conclusion: Provided $n \geq n_{\chi}$, there exists a unique $\alpha^{R F} \in\left[\frac{2}{(2 \chi-1) n+1}, \frac{1}{\chi}\right]$ such that $T S^{F}=T S^{R}$ and we have $T S^{R}>$ $T S^{F}$ for any $\alpha \in\left[\alpha^{R F}, \frac{1}{\chi}\right]$. For any $n<n_{\chi}$, we have $T S^{F}>T S^{R}$ for the interval considered. 


\section{References}

[1] Bekkers, R, Verspagen, B., Smits, J, 2002. Intellectual property rights and standardization: the case of GSM. Telecommunications Policy, Vol. 26.

[2] Caballero-Sanz, F., Moner-Coloques, R., Sempere-Monerris, J.J., 2002. Optimal Licensing in a Spatial Model. Annales d'Economie et de Statistique $66,257-279$.

[3] Chiao, B. , Lerner, J., Tirole, J., 2005. The Rules of Standard Setting Organizations: An Empirical Analysis. Harvard NOM Research Paper No. 05-05.

[4] Erutku, C., and Richelle, Y., 2007. Optimal Licensing Contracts and the Value of a Patent. Journal of Economics and Management Strategy, Vol. 16, No. 2.

[5] Kamien, M.I., 1992. Patent licensing. In: Aumann, R.J., Hart, S. (Eds.), Handbook of Game Theory with Economic Applications. Elsevier Science, North Holland, pp. 331-354 (Chapter 11).

[6] Kamien, M.I., Tauman, Y., 1986. Fees Versus Royalties and the Private Value of a Patent. The Quaterly Journal of Economics 101, 471-492.

[7] Kamien, M.I., Oren, S.S., Tauman, Y., 1992. Optimal Licensing of CostReducing Innovation. Journal of Mathematical Economics 21, 483-508..

[8] Lemley, M. A., 2002. Intellectual Property Rights and Standard Setting Organizations. California Law Review 1889. 
[9] Muto, S., 1993. On Licensing Policies in Bertrand Competition. Games and Economic Behavior 5, 257-267.

[10] Rostoker, M. 1984. A survey of corporate licensing. IDEA: Journal of. Law Technology. 24, 59-92.

[11] Sen, D., 2005. Fee versus Royalty Reconsidered, Games and Economic Behavior, 53, 141-147

[12] Shapiro, C., 2001, Navigating the Patent Thicket: Cross-Licenses, PatentPools, and Standard-Setting, in Jaffe, A., Lerner, J., Stern, S. (Eds.), Innovation Policy and the Economy, 1, 119-150.

[13] Simcoe, T., 2006 Explaining the Increase in Intellectual Property Disclosure. In: Sheri Bolin (editor). The Standards Edge: Golden Mean. Ann Arbor, Mich.: Bolin Communications.

[14] Taylor, C., Silberstone, Z., 1973. The Economic Impact of the Patent System. Cambridge Univ. Press, Cambridge.

[15] Vives, X., 1999. Oligopoly Pricing, Old Ideas and New Tools. MIT Press, Cambridge, MA.

[16] Wang, X. H., 2002. Fees Versus Royalty Licensing in a Differentiated Cournot Duopoly. Journal of Economics and Business 54, 253-266. 